\title{
Bentuk Dan Makna Inferensi Pada Tuturan Bahasa Indonesia Siswa Sekolah Dasar di Kecamatan Weru Cirebon
}

\section{Khalimi Romansyah}

Prodi Pendidikan Bahasa dan Sastra Indonesia, Universitas Swadaya Gunung Jati, Cirebon, Indonesia

Email Korespondensi: roman6086@gmail.com

\begin{abstract}
Abstrak. Tujuan penelitian ini menjelaskan bentuk dan makna inferensi pada tuturan bahasa Indonesia siswa sekolah dasar di Kecamatan Weru Cirebon. Penelitian ini merupakan penelitian deskriptif kualitatif. Sumber datanya yaitu dokumen, peristiwa tutur, dan informan. Teknik pengumpulan data melalui analisis dokumen, wawancara, dan observasi. Validitas data menggunakan teknik triangulasi sumber data dan teori. Analisis data dilakukan melalui reduksi data, penyajian data, dan penarikan simpulan. Hasil penelitian menunjukkan dari sepuluh peristiwa tutur ( terdiri atas lima puluh dua tuturan ) yang diamati, seluruhnya mengandung unsur inferensi. Bentuk inferensinya meliputi prinsip analogi penafsiran lokal sebanyak lima tuturan dan prinsip analogi penafsiran umum sebanyak enam tuturan. Adapun makna inferensinya meliputi : menyampaikan ajakan, menolak ajakan, memperingatkan sesuatu, mengumumkan sesuatu, menyampaikan keinginan, memberitahu sesuatu, mengingatkan sesuatu, menyuruh, dan mengharapkan sesuatu.
\end{abstract}

Kata kunci: Kecamatan Weru Cirebon, Bentuk dan Makna Inferensi, Tuturan, Siswa SD

Abstract: The purpose of this study is to explain the form and meaning of inference in Indonesian elementary school students' speech in the Weru District of Cirebon. This research is a qualitative descriptive study. Sources of data used are documents, speech events, and informants. Data collection techniques through document analysis, interviews, and observations. Data validity uses data source and theory triangulation techniques. Data analysis is performed through data reduction, data presentation, and get conclusions. The results showed that of the ten speech events (consisting of fifty-two utterances) observed, all contained inference elements. The form of inference includes the principle of the analogy of local interpretations of five utterances and the principle of analogy of general interpretation of six utterances. The meaning of inference includes: conveying an invitation, rejecting an invitation, warning something, announcing something, expressing a desire, telling something, reminding something, asking, and expecting something.

Keyword: Weru District Cirebon, Form And Meaning Of Inference, Speech, Elementary School Students

\section{Pendahuluan}

Komunikasi merupakan bentuk kegiatan yang mempunyai peranan sangat penting dalam kehidupan manusia sebab hanya dengan komunikasi, manusia dapat berinteraksi dengan sesamanya. Alat atau sarana komunikasi yang utama bagi manusia ialah bahasa karena sebagian besar komunikasi manusia dengan

Caruban: Jurnal Ilmiah Pendidikan Dasar 4(1), 34-43, Januari 2021

DOI: http://dx.doi.org/10.33603/.v4i1.3542, p-ISSN 2615-1391, e-ISSN 2620-3219

CProdi PGSD, Universitas Swadaya Gunung Jati 
sesamanya berupa kegiatan komunikasi berbahasa atau menggunakan media bahasa.

Komunikasi berbahasa mempunyai kelebihan dibandingkan dengan jenis komunikasi lainnya, seperti komunikasi dengan menggunakan gerak isyarat tangan dan komunikasi dengan membaca gerak bibir. Komunikasi berbahasa akan tetap berjalan walaupun dalam kondisi gelap sedangkan komunikasi gerak isyarat tangan atau membaca gerak bibir tidak dapat berjalan dalam kondisi gelap.

Komunikasi berbahasa akan komunikatif atau berjalan efektif apabila terjadi kesepahaman dari semua pihak yang terlibat yaitu pembicara atau penulis (penyapa) dan pendengar atau pembaca (pesapa). Namun kenyataan di lapangan masih sering terjadi komunikasi bahasa yang kurang efektif dan menimbulkan kesalahpahaman. Untuk itu dibutuhkan kerja sama komunikasi antara penyapa dengan pesapa. Salah satu bentuk kerja sama komunikasi berbahasa dari pesapa, yaitu upaya pesapa memahami atau mengerti makna, baik makna yang tersurat maupun makna yang tersirat dari tuturan yang diungkapkan penyapa, artinya pesapa akan mempertimbangkan atau memahami maksud penyapa, selain memahami makna tuturan. Upaya memahami makna yang tersirat (tidak tersurat) dalam tuturan biasa disebut inferensi.

Di samping alasan di atas, penulis juga mempertimbangkan hasil beberapa penelitian terkait yang dimuat pada jurnal pendidikan bahasa dan sastra Indonesia yaitu jurnal BASASTRA Vol. 2 No. 3 tahun 2014 ( ISSN 12302-6405 ). Untuk lebih jelasnya di bawah ini penulis akan mengemukakan hasil beberapa penelitian tersebut.

Penelitian pertama yaitu penelitian yang dilakukan Catur Handayani, Sumarwati, Raheni Suhita, yang berjudul Implikatur Percakapan dalam Acara Talk Show Mata Najwa Di Metro TV. Hasil penelitian ini menunjukkan bahwa percakapan pada acara Mata Najwa di Metro TV terdapat empat bentuk tuturan (empat bentuk tindak tutur) yang berimplikatur, yaitu representatif, direktif, komisif, dan ekspresif. Di samping itu percakapan pada acara Mata Najwa di Metro TV mengandung tujuh fungsi implikatur, yaitu memberi penjelasan, menyatakan harapan, memberikan saran, memberikan usulan, menunjukkan perasaan, berjanji, dan mengajak melakukan sesuatu.

Caruban: Jurnal Ilmiah Pendidikan Dasar 4(1), 34-43, Januari 2021

DOI: http://dx.doi.org/10.33603/.v4i1.3542, p-ISSN 2615-1391, e-ISSN 2620-3219

CProdi PGSD, Universitas Swadaya Gunung Jati 
Penelitian kedua yaitu penelitian yang dilakukan Aida Messayu Alfia, Muhammad Rohmadi, Purwadi, yang berjudul Pelanggaran Prinsip Kesantunan dan Implikatur Percakapan dalam Acara PAS Mantab Di TRANS 7. Hasil penelitian ini menunjukkan bahwa pelanggaran prinsip kesantunan dan implikatur percakapan membuat acara PAS Mantab lebih hidup, lebih menarik dan lebih mengesankan.

Penelitian ketiga yaitu penelitian yang dilakukan Sugeng Febry Andryanto, Andayani, Muhammad Rohmadi, yang berjudul Analisis Praanggapan pada Percakapan Tayangan Sketsa Di TRANS TV. Hasil penelitian ini menunjukkan bahwa percakapan Sketsa di Trans TV mengandung lima ragam tindak tutur yaitu tindak tutur representatif, direktif, komisif, deklaratif, dan ekspresif. Sebagian dari tindak tutur tersebut mengandung praanggapan. Di samping iitu dalam percakapan Sketsa juga terdapat implikatur konvensional dan non konvensional.

Berlandaskan uraian di atas, penulis termotivasi mengadakan penelitian yang berjudul Bentuk dan Makna Inferensi pada Tuturan Bahasa Indonesia Siswa Sekolah Dasar Di Kecamatan Weru Cirebon.

Bertitik tolak dari uraian latar belakang di atas, penulis mengemukakan beberapa rumusan masalah berikut: 1) bagaimanakah ragam bentuk inferensi tuturan bahasa Indonesia siswa SD di Kecamatan Weru Cirebon? 2) apa saja makna inferensi pada tuturan bahasa Indonesia siswa SD di Kecamatan Weru Cirebon?

\section{Metode Penelitian}

Sehubungan dengan penelitian ini, penulis menggunakan metode deskriptif kualitatif dengan pemerolehan data bersumber dari data primer dan data sekunder dengan rincian seperti di bawah ini.

Studi Lapangan

Berkenaan dengan pemerolehan data primer, penulis melakukan kegiatan pengamatan dan pencatatan terhadap 10 (sepuluh) peristiwa tutur bahasa Indonesia yang terjadi di seputar SD di Kec. Weru Cirebon. Peristiwa tutur yang penulis pilih adalah peristiwa tutur yang melibatkan sesama siswa SD.

Caruban: Jurnal Ilmiah Pendidikan Dasar 4(1), 34-43, Januari 2021

DOI: http://dx.doi.org/10.33603/.v4i1.3542, p-ISSN 2615-1391, e-ISSN 2620-3219

CProdi PGSD, Universitas Swadaya Gunung Jati 
Studi Pustaka

Berkenaan dengan pengumpulan data sekunder, penulis melakukan kegiatan kajian pustaka dari berbagai buku atau sumber yang berkaitan dengan masalah penelitian, utamanya tentang ragam bentuk dan makna inferensi.

\section{Hasil dan Pembahasan}

Hasil analisis terhadap sepuluh peristiwa tutur bahasa Indonesia siswa SD di Kecamatan Weru Cirebon membuktikan bahwa seluruh peristiwa tutur tersebut mengandung unsur inferensi. Adapun ragam bentuk dan ragam makna inferensinya akan penulis uraikan secara rinci di bawah ini. Dari sepuluh peristiwa tutur yang penulis analisis, terdapat enam peristiwa tutur yang mengandung bentuk inferensi prinsip analogi penafsiran umum (peristiwa tutur $1,5,6,7,9,10$ ) dan hanya lima peristiwa tutur yang mengandung bentuk inferensi prinsip analogi penafsiran lokal (peristiwa tutur 1, 2, 3, 4, 8). Sementara itu makna inferensi yang terkandung dalam sepuluh peristiwa tutur tersebut, meliputi : 1) Menyampaikan ajakan mengunjungi Pameran di Trusmi. 2) Menolak ajakan mengunjungi Pameran di Trusmi. 3) Memperingatkan ada guru pengawas kerapian pakaian siswa. 4) Memperingatkan jangan menggunakan WC bermasalah. 5) Mengumumkan nama lokasi perkemahan. 6) Menyampaikan keinginan meminjam kacu pramuka. 7) Memberitahu waktu belajar belum dimulai. 8) Mengingatkan hari libur dan tidak ada piket. 9) Menyuruh mencari di tempat jajanan milik Mas Agung. 10) Memberitahu hari besar (istimewa ) seorang Ibu. 11) Mengharapkan kemunculan tokoh-tokoh wanita generasi penerus bangsa.

Untuk lebih memperjelas uraian pembahasan di atas, di bawah ini penulis akan mengemukakan data tentang proses analisis dari sepuluh peristiwa tutur bahasa Indonesia siswa SD di Kecamatan Weru Cirebon.

\section{Peristiwa tutur 1}

Kegiatan : Berkumpul waktu istirahat sekolah.

Tempat : Halaman sekolah.

Peserta : A. B, C, dan D ( Siswa kelas 5 SD )

A : Hallo, teman-teman, ngomong-ngomong Trusmian sudah ramai,lho!

B : Ujian sudah dekat, coy!

A : Justru itu, kita perlu hiburan, bro!

C dan D : Setuju...... setuju. 
Peristiwa tutur 1 (percakapan 1) di atas mengandung unsur inferensi. Unsur inferensi tersebut terdapat pada tuturan Hallo, teman-teman, ngomong-ngomong Trusmian sudah ramai,lho! dan tuturan Ujian sudah dekat, coy! Untuk memahami makna yang tersirat (tidak tersurat) pada tuturan pertama, pesapa (lawan tutur) menggunakan prinsip analogi penafsiran lokal, yaitu penafsiran arti atau makna tuturan yang didasarkan pada kesamaan pengalaman atau kesepakatan pengetahuan sekelompok individu atau komunitas masyarakat tertentu. Sedangkan untuk memahami makna yang tersirat (tidak tersurat ) pada tuturan kedua, pesapa (lawan tutur) menggunakan prinsip analogi penafsiran umum yaitu penafsiran arti atau makna tuturan yang didasarkan pada pengetahuan umum atau kesamaan pengalaman masyarakat yang bersifat universal (pengetahuan tentang dunia). Adapun makna inferensi tuturan pertama ialah menyampaikan ajakan mengunjungi Pameran di Trusmi, sedangkan makna inferensi tuturan kedua ialah menolak ajakan mengunjungi Pameran di Trusmi.

\section{Peristiwa tutur 2}

Kegiatan : Persiapan mengikuti Upacara Bendera hari Senin.

Tempat : Halaman sekolah.

Peserta : A dan B (Siswa kelas 4 SD)

A : To, bajumu kok tidak dimasukkan sih. Pak Oman sudah datang lho!

B : Ah, kata siapa?

A : Tadi aku lihat sendiri.

B : Ma kasih, Di. (sambil buru-buru memasukkan baju seragamnya)

Peristiwa tutur 2 (percakapan 2) di atas mengandung unsur inferensi. Unsur inferensi tersebut terdapat pada tuturan Pak Oman sudah datang tho! Untuk memahami makna yang tersirat (tidak tersurat) pada tuturan tersebut, pesapa (lawan tutur) menggunakan prinsip analogi penafsiran lokal yaitu penafsiran arti atau makna tuturan yang didasarkan pada kesamaan pengalaman atau kesepakatan pengetahuan sekelompok individu atau komunitas masyarakat tertentu. Adapun makna inferensinya yaitu memperingatkan ada guru pengawas kerapian pakaian siswa.

\section{Peristiwa tutur 3}

Kegiatan : Mengajak teman ke toilet sekolah.

Tempat : Serambi sekolah.

Peserta : A dan B (Siswa kelas $4 \mathrm{SD}$ )

A : Man, antar aku ke WC, yu!

B : Nanti aku mau beli cilor dulu. 
A : Udah nanti aja beli cilornya.

B : Uuh, sebel ... jangan ke WC yang belakang, ah.

A : Nggak apa-apa.

B : Nggak mau.

A : Nggak usah takut.

B : Ya, udah, sendiri aja, sana!

Peristiwa tutur 3 (percakapan 3) di atas mengandung unsur inferensi. Unsur inferensi tersebut terdapat pada tuturan Uuh, sebel.. jangan ke WC yang belakang, ah. Untuk memahami makna yang tersirat (tidak tersurat) pada tuturan tersebut, pesapa (lawan tutur) menggunakan prinsip analogi penafsiran lokal. Adapun makna inferensinya yaitu memperingatkan jangan menggunakan WC bermasalah.

\section{Peristiwa tutur 4}

Kegiatan : Menyampaikan pengumuman lokasi perkemahan

Tempat : Ruang belajar (ruang kelas)

Peserta : A, B, dan C (Siswa kelas 6 SD)

A : Teman-teman, besok kita ke Cisaat bukan Cidomba. Jangan lupa bawa perlengkapan.

B : Jam berapa kumpul di sekolah?

A : Biasa, setengah sembilan.

C : Aku tidak ikut. Aku ijin. Kakiku masih sakit.

A : Yang penting besok kumpul di sini, biarpun nggak ikut kemah.

Peristiwa tutur 4 (percakapan 4) di atas mengandung unsur inferensi. Unsur inferensi tersebut terdapat pada tuturan Teman-teman, besok kita ke Cisaat bukan Cidomba. Untuk memahami makna yang tersirat (tidak tersurat) pada tuturan tersebut, pesapa (lawan tutur) menggunakan prinsip analogi penafsiran lokal. Adapun makna inferensinya yaitu mengumumkan nama lokasi perkemahan.

\section{Peristiwa tutur 5}

Kegiatan : Perbincangan pulang sekolah

Tempat : Di depan pintu gerbang sekolah

Peserta : A dan B (Siswa kelas 5 SD)

A : Din, besok ada pramuka, ya?

B : Iya, latihan PBB.

A : Pakaian?

Caruban: Jurnal Ilmiah Pendidikan Dasar 4(1), 34-43, Januari 2021

DOI: http://dx.doi.org/10.33603/.v4i1.3542, p-ISSN 2615-1391, e-ISSN 2620-3219

CProdi PGSD, Universitas Swadaya Gunung Jati 
B : Seragam lengkap.

A : Bawa kacunya dua, ya. Soalnya kacu saya hilang. Gak tahu tuh.

B : Oke, siap.

Peristiwa tutur 5 (percakapan 5) di atas mengandung unsur inferensi. Unsur inferensi tersebut terdapat pada tuturan Bawa kacunya dua, ya. Untuk memahami makna yang tersirat (tidak tersurat ) pada tuturan tersebut, pesapa (lawan tutur) menggunakan prinsip analogi penafsiran umum yaitu penafsiran arti atau makna tuturan yang didasarkan pada pengetahuan umum atau kesamaan pengalaman masyarakat yang bersifat universal (pengetahuan tentang dunia ). Adapun makna inferensinya ialah menyampaikan keinginan meminjam kacu pramuka.

\section{Peristiwa tutur 6}

Kegiatan : Berbincang sambil makan bakso

Tempat : Kantin sekolah

Peserta : A, B, dan C (Siswi kelas 5 SD)

A : Pit, cepat makan baksonya. Waktu istirahat sudah habis, lho.

B : Kan belum ada bel.

A : Mungkin Pak Mamat kelupaan atau aliran.

Yu, kita ke kelas saja. Barangkali Ibu Ida sudah masuk kelas. (A mengajakC)

C : Ayu, kami duluan, Pit.

Peristiwa tutur 6 (percakapan 6) di atas mengandung unsur inferensi. Unsur inferensi tersebut terdapat pada tuturan Kan belum ada bel. Untuk memahami makna yang tersirat (tidak tersurat) pada tuturan tersebut, pesapa (lawan tutur) menggunakan prinsip analogi penafsiran umum. Adapun makna inferensinya ialah memberitahu waktu belajar belum dimulai.

\section{Peristiwa tutur 7}

Kegiatan : Perbincangan pulang sekolah

Tempat : Di luar Pintu gerbang sekolah

Peserta : A dan B (Siswi kelas 6 SD)

A : Yan, besok kita berangkat lebih pagi, ya! Kita kan piket.

B : Besok tuh tanggal merah.

A : Oh, iya ya, aku lupa. Berarti kita bebas, dong!

B : Ya nggak lah. Pekerjaan rumah sudah numpuk. Tidak seperti kamu, bisa santai .

A : Sama saja, kok. Aku juga sibuk kalau di rumah.

Peristiwa tutur 7 (percakapan 7) di atas mengandung unsur inferensi. Unsur inferensi tersebut terdapat pada tuturan Besok tuh tanggal merah. Untuk 
memahami makna yang tersirat (tidak tersurat) pada tuturan tersebut, pesapa (lawan tutur) menggunakan prinsip analogi penafsiran umum. Adapun makna inferensinya ialah mengingatkan hari libur dan tidak ada piket.

\section{Peristiwa tutur 8}

Kegiatan : Melaksanakan perintah guru

Tempat : Serambi ruang belajar ( Serambi kelas)

Peserta : A, B, dan C (Siswi kelas 5 SD)

A : Tin, Aisyah mana? Suruh ke Ibu Juju !

B : Aku nggak tahu.

C : Coba aja di Mas Agung

A : Dia di sana?

C : Tadinya sih.

A : Uh! Anak tuh bikin repot aja.

Peristiwa tutur 8 (percakapan 8) di atas mengandung unsur inferensi. Unsur inferensi tersebut terdapat pada tuturan Coba aja di Mas Agung. Untuk memahami makna yang tersirat (tidak tersurat) pada tuturan tersebut, pesapa (lawan tutur ) menggunakan prinsip analogi penafsiran lokal. Adapun makna inferensinya yaitu menyuruh mencari di tempat jajanan milik Mas Agung.

\section{Peristiwa tutur 9}

Kegiatan : Perbincangan pulang sekolah

Tempat : Di luar pintu gerbang sekolah.

Peserta : A dan B (Siswi kelas 5 SD)

A : Lis, tumben kamu pulang sendirian. Emangnya Mama kamu ke mana?

B : Sekarang kan Hari Ibu.

A : Ooh, begitu ya?

B : Kalau Mama kamu, gimana?

A : Biasa aja, tapi Mama aku lagi ke rumah nenek.

Peristiwa tutur 9 ( percakapan 9) di atas mengandung unsur inferensi. Unsur inferensi tersebut terdapat pada tuturan Sekarang kan Hari Ibu. Untuk memahami makna yang tersirat (tidak tersurat) pada tuturan tersebut, pesapa (lawan tutur) menggunakan prinsip analogi penafsiran umum. Adapun makna inferensinya ialah memberitahu hari besar ( istimewa ) seorang Ibu.

\section{Peristiwa tutur 10}

Kegiatan : Pembentukan panitia Maulid Nabi

Tempat : Kantin sekolah 
Peserta : A dan B (Siswi kelas 6 SD)

A : Rin, kamu aku masukkan panitia Maulid Nabi, lho. Seksi dokumentasi .

B : Jangan lah, Si Misbah aja yang hobi photografi.

A : Aah! Kamu aja. Kata Bu Ana kan biar muncul Kartini-Kartini zaman now.

B : Bilang aja maksa.

A : Okey, siap yah.

Peristiwa tutur 10 (percakapan 10) di atas mengandung unsur inferensi. Unsur inferensi tersebut terdapat pada tuturan Kata Bu Ana kan biar muncul KartiniKartini zaman now. Untuk memahami makna yang tersirat (tidak tersurat) pada tuturan tersebut, pesapa (lawan tutur) menggunakan prinsip analogi penafsiran umum yaitu penafsiran arti atau makna tuturan yang didasarkan pada pengetahuan umum atau kesamaan pengalaman masyarakat yang bersifat universal (pengetahuan tentang dunia). Adapun makna inferensinya ialah mengharapkan kemunculan tokoh-tokoh wanita generasi penerus bangsa.

\section{Simpulan}

Berkenaan dengan rumusan masalah dan berlandaskan hasil pembahasan penelitian ini, penulis mengambil simpulan bahwa dari sepuluh peristiwa tutur bahasa Indonesia (terdiri atas lima puluh dua tuturan) yang diamati, seluruhnya mengandung bentuk dan makna inferensi. Bentuk inferensinya meliputi prinsip analogi penafsiran umum, yaitu peristiwa tutur 1, 5, 6, 7, 9, 10 (sebanyak enam tuturan) dan prinsip analogi penafsiran lokal yaitu peristiwa tutur 1, 2, 3, 4, 8 (sebanyak lima tuturan).

Adapun makna inferensinya meliputi: menyampaikan ajakan mengunjungi Pameran di Trusmi, menolak ajakan mengunjungi Pameran di Trusmi, memperingatkan ada guru pengawas kerapian pakaian siswa, memperingatkan jangan menggunakan WC bermasalah, mengumumkan nama lokasi perkemahan, menyampaikan keinginan meminjam kacu pramuka, memberitahu waktu belajar belum dimulai, mengingatkan hari libur dan tidak ada piket, menyuruh mencari di tempat jajanan milik Mas Agung, memberitahu hari besar (istimewa) seorang $\mathrm{Ibu}$, mengharapkan kemunculan tokoh-tokoh wanita generasi penerus bangsa.

Dalam kesempatan ini penulis berharap agar hasil penelitian ini dapat memperkaya khasanah ilmu pengetahuan, khususnya disiplin ilmu bahasa

Caruban: Jurnal Ilmiah Pendidikan Dasar 4(1), 34-43, Januari 2021

DOI: http://dx.doi.org/10.33603/.v4i1.3542, p-ISSN 2615-1391, e-ISSN 2620-3219

CProdi PGSD, Universitas Swadaya Gunung Jati 
Indonesia serta dapat dimanfaatkan sebagai referensi untuk kegiatan penelitian, khususnya studi sosiolinguistik dan pragmatik.

\section{Daftar Pustaka}

Alfia, A.M., Rohmadi, M. dan Purwadi. (2014). Pelanggaran Prinsip Kesantunan dan Implikatur Percakapan dalam Acara PAS Mantab Di TRANS 7. BASASTRA Jurnal Penelitian Bahasa Sastra Indonesia dan Pengajarannya 2(3). 1-18.

Alwi, H. dkk. (2003). Tata Bahasa Baku Bahasa Indonesia. Jakarta: Balai Pustaka.

Andryanto, S. F., Andayani, dan Rohmadi, M. (2014). Analisis Praanggapan pada Percakapan Tayangan Sketsa Di TRANS TV. BASASTRA Jurnal Penelitian Bahasa Sastra Indonesia dan Pengajarannya 2(3), 1-16.

Chaer, A. dan Agustina, L. (2004). Sosiolinguistik. Jakarta: Rineka Cipta.

Djajasudarma, T. F. (1989) Semantik II (Pemahaman Ilmu Makna). Bandung: Fak. Sastra, Universitas Padjajaran.

Djajasudarma, T. F. (2016). Wacana. Pemahaman dan Hubungan Antarunsur. Bandung: Refika Aditama.

Handayani, C., Sumarwati, dan Suhita, R. (2014). Implikatur Percakapan dalam Acara Talk show Mata Najwa Di Metro TV. BASASTRA Jurnal Penelitian Bahasa Sastra Indonesia dan Pengajarannya 2(3), 1-14.

Sugiyono. (2013). Metode Penelitian Kuantitatif, Kualitatif, dan RED. Bandung: Alphabeta.

Sumarsono. (2013). Sosiolinguistik. Yogyakarta: SABDA.

Yule, G. (2006). Pragmatik. Yogyakarta: Pustaka Pelajar.

Yule, G. (2015). Kajian Bahasa. Yogyakarta: Pustaka Pelajar. 